\title{
THE EFFECT OF LEAN TOOLS ON THE SAFETY LEVEL IN MANUFACTURING ORGANISATIONS
}

doi: $\quad 10.2478 /$ czoto-2019-0066

Date of submission of the article to the Editor: 2/11/2018

Date of acceptance of the article by the Editor: 19/12/2018

Robert Ulewicz ${ }^{1}$ - orcid id: 0000-0002-5694-4284

Livia V. Lazar ${ }^{2}$ - orcid id: 0000-0001-6203-1759

${ }^{1}$ Czestochowa University of Technology, Poland, robert.ulewicz@wz.pcz.pl

${ }^{2}$ University Politehnica of Buchares, Romania

Abstract: Lean Management is currently one of the best-known and is the most widely used management concepts in production enterprises. Lean creates such a culture of work in an organization that makes all participants in the organization interested in raising the level of quality, reducing costs and delivery time. However, there is no information about the influence of lean tools on the level of safety in production organizations. The paper presents the influence of five lean tools on the safety level by the example of metal manufacturing organization. The number of potentially dangerous situations and the number of accidents were taken as the measure of safety level. The obtained results indicates that the most important for the safety level is 5S, TPM while Kaizen, Poka-Yoka and VSM are smaller. The paper aims to broaden the knowledge about the dependence of the use of lean tools on the level of occupational safety.

Keywords: VSM, 5S, TPM, Poka-Yoke, Kaizen, Safety, Lean

\section{INTRODUCTION}

Managing a production enterprise is a big challenge, which is why it is worth trying to improve it using methods that are easy to implement. Thanks to practical solutions such as Lean Management, enterprises can improve production results (Mazur, 2016). This can be achieved with the help of easy and tailored tools (Kleszcz, 2018). As indicated by numerous works - enterprises achieve profitability improvement by implementing 5S practices (Anttila and Jussila, 2018) (Łyp-Wrońska and Tyczyński, 2018), Total Productive Maintenance (TPM), Value Stream Mapping (VSM) (Hines and Rich, 1997), Kazien and simple methods in the field of error proofing, e.g. PokaYoke (Garza-Reyes et al., 2018), (Shou et al., 2017) (Helmi et al., 2017). One of the important elements of business management in addition to profitability are issues related to occupational health and safety. Obligations that rest upon the employer are determined by normative acts and standards, which is why in company management they cannot be omitted. Including safety aspects in the business management process is very important from the point of view of efficiency, e.g. production, because 
inadequate working conditions may result in potentially accidental events that will result in material and non-material losses (Górny, 2018). Implementation of individual management elements (e.g. human resources management): planning, organizing, motivating and controlling cannot take place without paying attention to elements of occupational safety and health (OSH) (Woźny et al., 2018). The literature lacks information on the impact of lean tools on the level of safety in manufacturing enterprises (Zasadzien and Midor, 2015). The matter is even more complicated if we take into account the problems related to the implementation of solutions concerning Industry 4.0 (Nitkiewicz and Ayen, 2018) and a significant increase in productivity and product individualization (Kovács and Kot, 2017).

\section{LEAN MANUFACTURING EFFECT ON SAFETY LEVEL}

Incorrect organization of the production environment in the enterprise is the cause of many disruptions during the implementation of production processes (Onyusheva, 2017), (Ingaldi et al., 2018). The scale of disturbances is the greater, the more people employ the enterprise. Often, employees organize their work, guided by their own needs or habits acquired during their professional activity (Gembalska-Kwiecień et al., 2018). In addition to the disturbances typical of production sites, there are also disturbances in auxiliary processes (Pietraszek and Skrzypczak-Pietraszek, 2014). Observing the course of even the best designed and implemented production processes, it can be noticed that they do not run under ideal conditions, i.e. they are not disturbed by any factors. Two types of interference affect each process: random and special (Pietraszek et al., 2016). Random factors usually occur in a large number, each of them having a relatively small meaning, leading to variability that must necessarily be identified. Random factors generate disturbances, which should always be counted, their source is not always known and they affect the parameters of the manufacturing process in a continuous manner with random intensity. They cannot be fully eliminated, but usually their impact is small and results in a slight statistical differentiation of the value of the products' features. The improvement of the process quality can be achieved through organizational changes so as to limit the number of random factors affecting the process or change the process to another (Maszke et al., 2018). By reducing the random factors affecting the process, we also reduce the probability of potentially dangerous situations, which affects the safety level in the production company. Much more disadvantageous due to the quality of the manufacturing process as well as the level of safety are special interferences (Kotus et al., 2018). Special interferences can be detected and identified as causing changes in the process level. These are interferences most often from the outside, occurring suddenly or their impact is systematic and intensifying (Shrimali et al., 2018). They affect significantly the parameters of the manufacturing process as well as the level of safety. The use of lean tools, for example $5 S$ practices, directly affects the reduction of potentially dangerous events (Gálová et al., 2018). On the other hand, JIT practices can cause internal transport problems by increasing the frequency of deliveries and increasing the possibility of occurrence of a potentially dangerous event (Cusumano, 1994). Using a suction system based on Kanban cards, we can achieve a significant variety of products thanks to a faster exchange system (Ulewicz et al., 2016). This is positive from the point of view of marketing, because the diversity of the product and its personalization (the objective of Industry 4.0) generates greater demand for products (Stasiak-Betlejewska et al., 2018). Based on the literature data, 
it can be assumed that the know-how and skills acquired during the use of lean tools are beneficial for improving work safety through better understanding of processes as well as potentially dangerous events (Blaskova et al., 2017). VSM can also help to identify the impact of selected factors on the level of safety in an enterprise. Total Productive Maintenance through a comprehensive program of continuous development of employees and organizations and changes in the culture of the production plant in order to maximize the efficiency of machinery and equipment, through constant monitoring and supervision of technical infrastructure provide employees with an attractive and safe work environment while achieving maximum efficiency and productivity.

\section{RESEARCH METHODOLOGY}

The research was carried out in metal industry production companies. Initial research aimed at the selection of the research sample consisted of 200 business entities in the segment of small and medium-sized enterprises. As a result of the conducted surveys aimed at determining: knowledge of lean tools, their actual use and determining whether given entity has implemented OHSAS/ PN-N-18001 or ISO 45001 safety management system only 20 entities qualified for final tests qualified meeting the assumed conditions. The classification criteria for the research group were: lack of a work safety management system, minimum 3-year period of using lean tools in the enterprise, 5 years of production activity and consent to provide documentation or information on potentially dangerous events and accidents, if any. There were established the scope of applied lean tools based on the surveys which were extended by direct interview. In the surveys, there was used a direct and auditory questionnaire using the Likert scale. The qualifying element was the answer regarding the use of individual lean tools in the enterprise. The entities were qualified with the assessment:

- 4 - I rather agree that the tool (e.g. visual control) is used by the enterprise and

- 5 - I strongly agree that the tool (e.g. pull system) is used by the enterprise.

Table 1 presents the identified lean tools used in the qualified research group of 20 manufacturing enterprises from metal sector of the SME's.

Table 1

Identified lean tools used in research group entities

\begin{tabular}{|l|l|l|}
\hline \multicolumn{3}{|c|}{ Lean manufacturing methods and tools } \\
\hline Pull system & TPM & VSM \\
\hline Takt time & OEE & Current state map \\
\hline Leveled production & SMED & Future state map \\
\hline Visual control & $5 S$ & Flow diagrams \\
\hline Kanban & Error proofing/Poka-Yoke & Safety cross \\
\hline
\end{tabular}

In the research, a comparative group of companies from the metal sector of the SME sector was used for which the following selection criteria were established: 
- the lack of formalized lean tools and practices,

- no safety management system PN-N-18001/ OHSAS 18001 or ISO 45001,

- minimum 5 years of production activity,

- consent to share information on potentially dangerous incidents and accidents, insofar as they have occurred.

\section{RESULTS}

The research results are based on 20 production companies with five years of production experience and a minimum 3-year period of application of lean tools. At the beginning, there was determined the correlation dependence between the period of use of lean tools and the number of potentially dangerous incidents reported (Table 2 and Fig. 1).

Table 1

List of the number of potentially dangerous incidents during the period of using lean tools

\begin{tabular}{|l|l|l|l|}
\hline No. & $\begin{array}{l}\text { Years of using lean } \\
\text { tools }\end{array}$ & $\begin{array}{c}\text { Number of potentially } \\
\text { dangerous events during the } \\
\text { period of using lean tools }\end{array}$ & $\begin{array}{c}\text { Average number of } \\
\text { potentially dangerous } \\
\text { events per year }\end{array}$ \\
\hline 1. & 3 & 5.0 & 15 \\
\hline 2. & 5 & 2.8 & 14 \\
\hline 3. & 6 & 3.5 & 21 \\
\hline$\ldots$ & $\ldots$ & $\ldots$ & $\ldots$ \\
\hline 20. & 5 & 2.2 & 11 \\
\hline
\end{tabular}

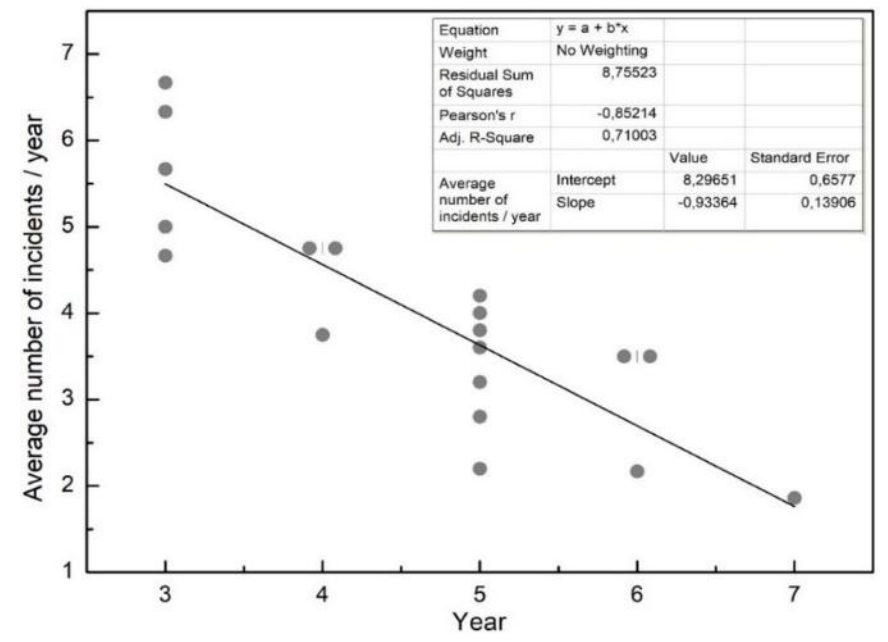

Fig. 1. Correlation chart of scatter of points - dependence of the number of critical incidents on the period of using lean tools

The obtained results indicate that between the analysed features: the number of critical incidents and the number of years of using lean tools there is a strong negative dependency. With the passage of time and gaining experience in the use of lean tools, the number of potentially dangerous events decreases. Analysing the coefficient of determination for the presented data, we can state that $72.6 \%$ of the variability of critical incidents is explained by the time of using the lean tools. Referring the results to enterprises that do not use lean tools, we observe a significant reduction in critical incidents in the time period under consideration, and the reduction of potentially dangerous incidents amounted to nearly $40 \%$. 
In order to determine the weight of individual lean tools on the level of safety in the research group, employees (20 employees from each of 20 objects) were asked to indicate the weight of each of the five lean tools by placing it in the appropriate position in the hierarchy of validity. Then, the $W$ Severity Rating was calculated (Ulewicz and Nowicka-Skowron, 2017) (Fig. 2). The limitation to the five tools is due to the fact that they are used in all analysed 20 entities.

$$
W=\frac{\sum_{i=1}^{k} n_{i} w_{i}}{k \sum_{i=1}^{k} n_{i}}
$$

where:

$W$ - Severity Rating,

$i$ - indication of tools place,

$k$ - the maximum weight (indication of the order of the tools meant assigning weights

in reverse order),

$n_{i}$ - number of indications of given tools on $i$-number place,

$w_{i}$ - weight corresponding to the place of $i$ tools.

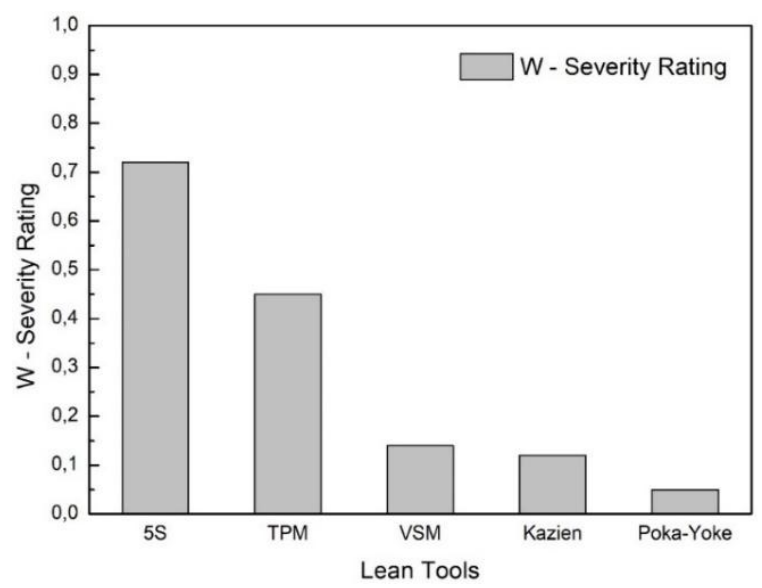

Fig. 2. The impact of selected lean tools on the level of safety in metallurgical industry of manufacturing enterprises

\section{CONCLUSION}

The article presents the results of the research on the relationship and impact of the selected (basic) lean tools (5S, TPM, VSM, Kaizen, Poka-Yoke) on the level of occupational safety in small and medium-sized metal manufacturing enterprises. As a measure of safety, the number of potentially dangerous incidents recorded on the premises of the company was taken. In the examinations were used extended surveys. A correlation was determined between the number of potential critical events and the period of use of lean tools. Based on the rank indicator, there was determined the importance of the applied lean tools on the level of safety in the employees' assessment. The results obtained will fill the information gap regarding the influence of lean tools on the level of work safety. The research confirms the positive effect of lean tools on the level of safety as a function of time as well as the strength of the effect of selected tools in the aspect of employee's evaluation. The presented research results are a prelude to extended research aimed at supplementing the knowledge of the impact of individual tools not only on the level of efficiency, quality 
but also safety in the aspect of the challenges posed by modern production systems as well as the inevitable technical revolution 4.0. Similar methodology appears to be useful in a design of hydraulic for heavy duty machines (Domagała et al., 2018a; Domagała et al., 2018b) or estimation of a life-time of parts (Osocha, 2018) even including special methods of materials science e.g. a fuzzy uncertainty estimation (Pietraszek, 2012; Pietraszek et al., 2017), the image analysis (Gadek-Moszczak et al., 2015; Gadek-Moszczak and Korzekwa, 2017). It may be also fruitful in machining e.g. a surface improvement (Zorawski et al., 2008; Radek et al., 2017; Radek et al., 2018a; Pliszka et al., 2018; Radek et al. 2018b) or a special sintering (Tiziani et al., 1990). It can be also useful in such seemingly distant industries as biotechnology (Skrzypczak-Pietraszek et al., 2018a; Skrzypczak-Pietraszek et al., 2018b) or high energy physics infrastructure (Singh et al., 2016).

\section{ACKNOWLEDGEMENTS}

This publication is under the project "Curriculum Development of Master's Degree Program in Industrial Engineering for Thailand Sustainable Smart Industry (MSIE4.0)" that has been funded with support from the European Commission (Project Number: 586137-EPP-1-2017-1-TH-EPPKA2-CBHE-JP).

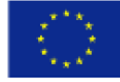

\section{REFERENCES}

Anttila, J., Jussila, K., 2018. Organizational Learning in Developing the Integrated Quality Management. Production Enginering Archives 18, 3-13, https://doi.org/10.30657/pea.2018.18.01

Blaskova, M., Blasko, R., Rosak-Szyrocka, J., Ulewicz, R., 2017. Flexibility and Variability of Motivating Employees and Managers in Slovakia and Poland. Polish J. Manag. Stud. 15, 26-36, https://doi.org/10.17512/pjms.2017.15.1.03

Cusumano, M., 1994. The Limits of" Lean". Sloan Manage. Rev. 35, 27-32. https://doi.org/10.1109/TASE.2010.2041450

Domagala, M., Momein, H., Domagala-Fabis, J., Filo, G., Kwiatkowski, D., 2018a. Simulation of cavitation erosion in hydraulic valve. Terotechnology, 2017, 5, 1-6.

Domagala, M., Momeni, H., Domagala-Fabis, J., Filo, G., Krawczyk, M., Rajda, J., 2018b. Simulation of particle erosion in a hydraulic valve. Terotechnology, 2017, 5, 17-24.

Gadek-Moszczak, A., Pietraszek, J., Jasiewicz, B., Sikorska, S., Wojnar, L., 2015. The bootstrap approach to the comparison of two methods applied to the evaluation of the growth index in the analysis of the digital $x$-ray image of a bone regenerate. New Trends in Comput. Collective Intelligence, 572, 127-136.

Gadek-Moszczak, A., Korzekwa, J. (2017). Application of the image analysis methods for quantitative description of the $\mathrm{Al}_{2} \mathrm{O}_{3} / W S_{2}$ oxide layers wear mechanism. Metal 2017: $26^{\text {th }}$ Int. Conf. on Metallurgy and Materials, 1264-1269.

Gálová, K., Rajnoha, R., Ondra, P., 2018. The Use of Industrial Lean Management Methods in the Economics Practice: An Empirical Study of the Production Companies in the Czech Republic. Polish J. Manag. Stud. 17, 93-104.

Garza-Reyes, J.A., Kumar, V., Chaikittisilp, S., Tan, K.H., 2018. The effect of lean methods and tools on the environmental performance of manufacturing organisations. Int. J. Prod. Econ. 200, 170-180.

Gembalska-Kwiecień, A., Skotnicka-Zasadzień, B., Wolniak, R., Bujna, M., 2018. Creating Participation of Employees in Improving Work Safety in Enterprise. 
Multidiscip. Asp. Prod. Eng. 1, 689-694, https://doi.org/10.2478/mape-2018-0087

Górny, A., 2018. Safety in ensuring the quality of production - the role and tasks of standards requirements. MATEC Web Conf. 183, 01005, https://doi.org/10.1051/matecconf/201818301005

Helmi, S.A., Nordin, N.N., Hisjam, M., 2017. Errors prevention in manufacturing process through integration of Poka Yoke and TRIZ. p. 020025, https://doi.org/10.1063/1.5010642

Hines, P., Rich, N., 1997. The seven value stream mapping tools. Int. J. Oper. Prod. Manag. 17, 46-64, https://doi.org/10.1108/01443579710157989

Ingaldi, M., Dziuba, S.T., Cierniak-Emerych, A., 2018. Analysis of problems during implementation of Lean Manufacturing elements. MATEC Web Conf. 183, 01004, https://doi.org/10.1051/matecconf/201818301004

Kleszcz, D., 2018. Barriers and Opportunities in the Implementation of Lean Manufacturing In The Ceramic Industry. Prododuction Enginering Archives 19, 4852, https://doi.org/10.30657/pea.2018.19.10

Kotus, M., Koloman, K., Hudec, M., 2018. Assessment of Wood Processing Safety in the Production Organization. Multidiscip. Asp. Prod. Eng. 1, 727-737, https://doi.org/10.2478/mape-2018-0092

Kovács, G., Kot, S., 2017. Economic and social effects of novel supply chain concepts and virtual enterprises. J. Int. Stud. 10, 237-254, https://doi.org/10.14254/20718330.2017/10-1/17

Łyp-Wrońska, K., Tyczyński, B., 2018. Analysis of the $5 S$ method in production enterprise - case study. MATEC Web Conf. 183, 01016, https://doi.org/10.1051/matecconf/201818301016

Maszke, A., Dwornicka, R., Ulewicz, R., 2018. Problems in the Implementation of the Lean Concept at a Steel Works - Case Study. MATEC Web Conf. 183, 01014, https://doi.org/10.1051/matecconf/201818301014

Mazur, M., 2016. Assumptions concept of LEAN processes in the organization of the work on example the production of building components. Prododuction Enginering Archives 13/4, 41-43.

Nitkiewicz, T., Ayen, Z., 2018. Identifying key criteria in development of Industrial Engineering education. MATEC Web Conf. 183, 04008, https://doi.org/10.1051/matecconf/201818304008

Onyusheva, I., 2017. Analytical and Managerial Issues of Human Capital in Conditions Of Global Competitiveness: The Case of Kazakhstan. Polish J. Manag. Stud. 16, 198-209, https://doi.org/10.17512/pjms.2017.16.2.17

Osocha, P., 2018. Calculation of Residual Life for P91 Material Based on Creep Rate and Time to Rupture. Mater. Res. Proc. 5, 177-182.

Pietraszek, J., 2012. Fuzzy Regression Compared to Classical Experimental Design in the Case of Flywheel Assembly. Artificial Intelligence and Soft Computing, Pt I, 7267, 310-317.

Pietraszek, J., Kolomycki, M., Szczotok, A., Dwornicka, R., 2016. The Fuzzy Approach to Assessment of ANOVA Results, in: Nguyen, NT and Manolopoulos, $Y$ and Iliadis, $\mathrm{L}$ and Trawinski, B (Ed.), Computational Collective Intelligence, ICCCI 2016, PT I, Lecture Notes in Artificial Intelligence, 260-268.

Pietraszek, J., Skrzypczak-Pietraszek, E., 2014. The Optimization of the Technological Process with the Fuzzy Regression, in: Szczotok, A et al. (Eds.), Terotechnology, Advanced Materials Research. p. 151+.

Pietraszek, J., Szczotok, A., Kolomycki, M., Radek, N., Kozien, E., 2017. Nonparametric assessment of the uncertainty in the analysis of the airfoil blade traces. 
Metal 2017: $26^{\text {th }}$ Int. Conf. on Metallurgy and Materials, 1412-1418.

Pliszka, I., Radek, N., Gadek-Moszczak, A., Fabian, P., Paraska, O., 2018. Surface improvement by WC-Cu electro-spark coatings with laser modification. Terotechnology, 2017, 5, 237-242.

Radek, N., Broncek, J., Fabian, P., Pietraszek, J., Dudek, A., 2017. Tribological properties of electro-spark deposited coatings after laser treatment. Proc. $58^{\text {th }}$ Int. Conf. Machine Design Departments (ICMD 2017). Czech Univ. Life Sci. Prague, Kamycka 129, Prague 6165 21, Czech Republic, 314-319.

Radek, N., Szczotok, A., Gadek-Moszczak, A., Dwornicka, R., Broncek, J., Pietraszek, J., 2018a. The impact of laser processing parameters on the properties of electro-spark deposited coatings. Arch. Metall. Mater., 63, 809-816.

Radek, N., Pietraszek, J., Szczotok, A., 2018b. Microstructure and tribological properties of esd coatings after laser processing. Mater. Res. Proc. 5, 206-209.

Shou, W., Wang, J., Wu, P., Wang, X., Chong, H.-Y., 2017. A cross-sector review on the use of value stream mapping. Int. J. Prod. Res. 55, 3906-3928, https://doi.org/10.1080/00207543.2017.1311031

Shrimali, A.K., Soni, V.K., Pawar, S.S., 2018. Interpretive Structural Modeling of identified Barriers to Lean Implementation in SMEs. MATEC Web Conf. 183, 01008, https://doi.org/10.1051/matecconf/201818301008

Singh, B. et al., 2016. Study of doubly strange systems using stored antiprotons. Nucl. Phys. A 954, 323-340.

Skrzypczak-Pietraszek, E., Piska, K., Pietraszek, J., 2018a. Enhanced production of the pharmaceutically important polyphenolic compounds in Vitex agnus castus $L$. shoot cultures by precursor feeding strategy. Eng. Life Sci. 18, 287-297.

Skrzypczak-Pietraszek, E., Reiss, K., Zmudzki, P., Pietraszek, J., 2018b. Enhanced accumulation of harpagide and 8-O-acetyl-harpagide in Melittis melissophyllum L. agitated shoot cultures analyzed by UPLC-MS/MS. PLoS ONE 13, e0202556.

Stasiak-Betlejewska, R., Parv, L., Gliń, W., 2018. The Influence of Industry 4.0 on the Enterprise Competitiveness. Multidiscip. Asp. Prod. Eng. 1, 641-648, https://doi.org/10.2478/mape-2018-0081

Tiziani, A., Molinari, A., Kazior, J., Straffelini, G., 1990. Effect of vacuum sintering on the mechanical-properties of copper-alloyed stainless-steel. Powder Metall. Int. 22, 17-19.

Ulewicz, R., Jelonek, D., Mazur, M., 2016. Implementation of Logic Flow in Planning and Production Control. Manag. Prod. Eng. Rev. 7, 89-94, https://doi.org/10.1515/mper-2016-0010

Ulewicz, R., Nowicka-Skowron, M., 2017. Total Quality Management in the Practice of Polish Metallurgical Enterprises, in: Metal 2017: 26th International Conference on Metallurgy and Materials. Tanger Ltd, Keltickova 62, Slezska, Ostrava 710 00, Czech Republic, 2338-2343.

Woźny, A., Dobosz, M., Saja, P., 2018. Budowanie Strategii Zarządzania BHP w Przedsiębiorstwie. Qual. Prod. Improv. 08, 75-83, https://doi.org/10.30657/qpi.2018.08.07

Zasadzien, M., Midor, K., 2015. Innovative Application Of Quality Management Tools In A Hard Coal Mine, in: Science And Technologies In Geology, Exploration And Mining, SGEM 2015, Vol III, International Multidisciplinary Scientific GeoConference-SGEM, 415-422.

Zorawski, W., Chatys, R., Radek, N., Borowiecka-Jamrozek, J., 2008. Plasmasprayed composite coatings with reduced friction coefficient. Surface \& Coatings Technology, 202, 18, 4578-4582. 